\title{
Correction to: Management of early ankle osteoarthritis through anterior joint-preserving surgery: a retrospective evaluation at mid- to long-term follow-up
}

\author{
Massimiliano Mosca ${ }^{1}$ - Silvio Caravelli ${ }^{1}$ [ $\cdot$ Mario Fuiano $^{1} \cdot$ Simone Massimi $^{1} \cdot$ Danila Oldani $^{2} \cdot$ Laura Rossi $^{2}$.
} Alberto Grassi ${ }^{1} \cdot$ Stefano Zaffagnini ${ }^{1} \cdot$ Francesco Ceccarelli $^{2}$

Published online: 24 June 2020

(c) Springer-Verlag France SAS, part of Springer Nature 2020

\section{Correction to: \\ European Journal of Orthopaedic Surgery \& \\ Traumatology \\ https://doi.org/10.1007/s00590-020-02691-6}

The original version of this article unfortunately contained a mistake. The spelling of the name 'Francesco Ceccarelli' was incorrect.

The original article has been corrected.

Publisher's Note Springer Nature remains neutral with regard to jurisdictional claims in published maps and institutional affiliations.

The original article can be found online at https://doi.org/10.1007/ s00590-020-02691-6.

Silvio Caravelli

doct.car@gmail.com

1 II Clinic of Orthopaedics and Traumatology, IRCCS Istituto

Ortopedico Rizzoli, Via Pupilli 1, 40136 Bologna, Italy

2 Clinica Ortopedica, Azienda Ospedaliero-Universitaria

Parma, Parma, Italy 